\title{
Impactos das Mudanças Climáticas em uma Bacia Hidrográfica no Sul do Estado de Minas Gerais
}

\author{
Estefânia Maria Sousa Zákhia ${ }^{1}$ (D), Lívia Alves Alvarenga ${ }^{1}$, Javier Tomasella ${ }^{2}$, \\ Minella Alves Martins ${ }^{2}$, Ana Carolina Nascimento Santos ${ }^{2}$, Pâmela Aparecida Melo ${ }^{1}$ \\ ${ }^{I}$ Departamento de Recursos Hídricos e Saneamento, Universidade Federal de Lavras, Lavras, \\ $M G$, Brasil. \\ ${ }^{2}$ Centro Nacional de Monitoramento e Alertas de Desastres Naturais, Instituto Nacional de \\ Pesquisas Espaciais, Cachoeira Paulista, SP, Brasil.
}

Recebido em: 21 de Janeiro de 2021 - Revisado em: 6 de Março de 2021 - Aceito em: 22 de Outubro de 2021

\section{Resumo}

\begin{abstract}
As mudanças climáticas no século XXI é uma realidade inconteste. Diversos efeitos e impactos vêm sendo registrados em várias regiões do planeta. Este trabalho tem por objetivo avaliar a associação do modelo hidrológico MHD-INPE ao modelo atmosférico Eta/CPTEC, a fim de simular o impacto de mudanças climáticas na Bacia Hidrográfica do Ribeirão Jaguara, localizada no sul do estado de Minas Gerais. Para tal fim, foram utilizados dois cenários (RCP4.5 e RCP8.5) de três modelos globais (HadGEM2-ES, MIROC5 e CanESM2), regionalizados pelo modelo Eta. Os resultados da calibração e validação mostraram uma boa performance MHD-INPE em simular a vazão da BHRJ. Após a correção de viés, as saídas dos cenários foram usadas como entrada no MHD-INPE. As projeções climáticas corrigidas dos cenários resultaram em predominante redução da precipitação ao longo do século. Os resultados das projeções da temperatura mostraram aumento consensual por parte dos modelos climáticos, em ambos os cenários. As estatísticas da curva de permanência das vazões advindas das simulações climáticas mostraram um bom desempenho do MHD-INPE na simulação do clima presente.
\end{abstract}

Palavras-chave: modelagem hidrológica, correção de viés, MHD-INPE.

\section{Climate Change's Impacts in a Watershed in the South of the Minas Gerais}

\section{State}

\begin{abstract}
Climate change in the 21st century is an undisputed reality. Several effects and impacts have been registered in society in several regions of the planet. This work objective is to evaluate an association of the hydrological model MHD-INPE with the atmospheric model Eta/CPTEC to simulate the impact of climate change in the Jaguara Creek Basin, located in the south of the state of Minas Gerais. For this purpose, two scenarios (RCP4.5 and RCP8.5) of three global climatic models downscaled by the Eta model (HadGEM2-ES, MIROC5 and CanESM2) were used. The results of the calibration and validation shows a good performance of the MHD-INPE model in simulating the JCR daily discharge. The results of the scenarios were used as input to the MHD-INPE model after bias correction. Regarding the corrected climate projections, they resulted in a predominant reduction of the rainfall throughout the 21 st century. The results of the projections of temperature showed an increase through the climatic models in both scenarios. The statistical of the flow duration curve (FDC) resulting from the simulations of the Eta model showed a good performance of the MHD-INPE in the simulation of the baseline period.
\end{abstract}

Keywords: hydrological modelling, bias correction, MHD-INPE.

\section{Introdução}

A região sudeste, a qual possui a maior densidade populacional do Brasil, é socialmente e economicamente caracterizada como a mais relevante na trajetória de desenvolvimento do país. Nos anos hidrológicos de 20132014 e 2014-2015, essa região sofreu uma grave crise

Autora de correspondência: Estefânia Maria Sousa Zákhia, estefstew@gmail.com. 
hídrica, devido à redução drástica da precipitação e elevadas temperaturas no verão. Além disso, a crise hídrica nessa região pode ser atribuída a uma série de fatores, tais como: desigualdades socioespaciais, infraestrutura deficiente, políticas inadequadas para a gestão de recursos hídricos, desmatamento da Mata Atlântica, dentre outros (Alvarenga et al., 2018; Lyra et al., 2017; Marengo et al., 2015). As consequências da escassez hídrica no Brasil vão além das dificuldades de acesso para o consumo humano, afetando gravemente a oferta de alimentos e a geração de energia elétrica no país (Hunt et al., 2018; Marengo et al., 2015; Martins et al., 2018; Martins et al., 2019).

O bem-estar das sociedades humanas está intimamente associado à variabilidade climática. Este relacionamento é especialmente forte em regiões onde a economia baseia-se na agricultura ou onde existe uma forte dependência da vazão do curso d'água para a geração de eletricidade (Nóbrega et al., 2011) que é o caso da Bacia Hidrográfica do Rio Grande (BHRG). Sua localização na região sudeste do Brasil é estratégica para o setor de produção de energia elétrica do país, especialmente em sua região de cabeceiras, onde concentra-se uma sequência de grandes reservatórios que também são essenciais para regular a vazão da bacia hidrográfica (Mello et al., 2015; Viola et al., 2015).

Diversos autores (Mello et al., 2015; Nóbrega et al., 2011; Oliveira et al., 2017; Viola et al., 2014, 2015) avaliaram os efeitos das mudanças climáticas nos recursos hídricos na região de cabeceiras do Rio Grande, visto que as mudanças do clima envolvem interações complexas em escala global que podem impactar a disponibilidade hídrica em escalas menores. No entanto, sabe-se que avaliar as mudanças climáticas em uma bacia hidrográfica heterogênea $\left(145.000 \mathrm{~km}^{2}\right)$ como a BHRG implica em resultados questionáveis para aqueles que atuam em diferentes atividades cotidianas na escala local, tornando necessária uma análise refinada em bacias de pequeno porte.

Nesse contexto, optou-se por avaliar as projeções climáticas na Bacia Hidrográfica do Ribeirão Jaguara (BHRJ), localizada na região de cabeceiras do Rio Grande, sul do estado de Minas Gerais. Trata-se de uma bacia de $33 \mathrm{~km}^{2}$ representativa dessa região que vem sendo monitorada desde 2006 pela Universidade Federal de Lavras (UFLA) com apoio da Companhia Energética de Minas Gerais (CEMIG) e da Agência Nacional de Energia Elétrica (ANEEL). Desde então, inúmeros estudos (Alves et al., 2019; Andrade et al., 2012; Beskow et al., 2011a, b; 2018) foram realizados na BHRJ, dentre eles, a aplicação dos modelos hidrológicos LASH (Beskow et al., 2011a) e SWAT (Andrade et al., 2012), que apresentaram desempenho adequado a bacia, obtendo coeficientes NashSutcliffe (NSE) de 0,820 e 0,764 com o LASH de 0,660 e 0,872 com o SWAT, para a calibração e validação da vazão, respectivamente.
Diferentes modelos hidrológicos têm sido utilizados para avaliar os impactos das mudanças climáticas na hidrologia. Dentre eles, elenca-se o Modelo Hidrológico Distribuído (MHD-INPE) (Rodriguez e Tomasella, 2016), desenvolvido no Instituto Nacional de Pesquisas Espaciais (INPE), que consiste numa adaptação do Modelo de Grandes Bacias (MGB-IPH) do Instituto de Pesquisas Hidráulicas (IPH). O MHD-INPE tem sido recentemente aplicado em simulações hidrológicas de bacias hidrográficas de pequeno (Melo, 2019), médio (Casagrande et al., 2017) e grande porte (Falck et al., 2015; Siqueira Júnior et al., 2015) no Brasil e se destaca pela possibilidade de ser alimentado pelo modelo atmosférico Eta/CPTEC, assim como por qualquer outro modelo climático.

Modelos climáticos possibilitam a previsão das condições do tempo para dias consecutivos e possuem a habilidade de projetar o clima na próxima estação ou simular características gerais do clima futuro, levando em consideração as modificações antropogênicas, como o aumento de emissão de gases de efeito estufa, aerossóis e as mudanças no uso e ocupação dos solos (Sampaio e Dias, 2014). Os modelos climáticos se subdividem em modelos climáticos globais (MCGs), que possuem resolução espacial horizontal de centenas de quilômetros e modelos climáticos regionais (MCRs), que possuem um domínio limitado e resolução espacial na ordem de dezenas de quilômetros, permitindo enxergar e resolver características do sistema terrestre não elencadas nos MCGs (Sales et al., 2015).

O progresso nos MCRs tornou mais atraente o uso de simulações provenientes destes como base para estudos hidrológicos (Teutschbein e Seibert, 2012). A regionalização (downscaling) dos resultados advindos de MCGs por meio de MCRs de alta resolução sobre a área de interesse é a técnica mais viável para escalonar as variáveis de baixa resolução espacial dos modelos globais para escalas locais mais refinadas. Nessa técnica, os modelos regionais adotam como condições de contorno nas laterais do domínio geográfico os dados provenientes dos modelos climáticos globais (Oliveira et al., 2017; Sampaio e Dias, 2014).

Dessa forma, considerando as premissas citadas anteriormente, o objetivo do presente estudo consiste em aplicar o modelo hidrológico MHD-INPE e avaliar o desempenho do mesmo numa bacia de pequeno porte (BHRJ) que vem sendo severamente degradada ao longo dos últimos anos. Além disso, serão avaliados os possíveis impactos hidrológicos na vazão futura da BHRJ simulada pelo MHD-INPE, por meio da curva de permanência das vazões e pelo método de Budyko.

\section{Materiais e Métodos}

Para análise das vazões sob impactos das mudanças climáticas, foram estabelecidas algumas etapas, tais como a modelagem hidrológica da bacia hidrográfica, avaliação 
e correção das projeções climáticas futuras e aplicação destas junto ao modelo escolhido. Após todas as etapas, as metodologias estatísticas utilizadas possibilitaram o estudo dos impactos das mudanças climáticas nas descargas da bacia hidrográfica.

\section{1. Área de estudo}

A Bacia Hidrográfica do Ribeirão Jaguara (BHRJ), localizada entre as coordenadas geográficas $-44^{\circ} 24^{\prime} 54^{\prime \prime} \mathrm{e}$ $-44^{\circ} 31^{\prime} 01^{\prime \prime}$ de longitude Oeste e $-21^{\circ} 13^{\prime} 47^{\prime \prime}$ e $-21^{\circ} 17^{\prime} 24^{\prime \prime}$ de latitude Sul, faz parte da unidade geomorfológica do Planalto Campos das Vertentes, na Região do Alto Rio Grande, no sul estado de Minas Gerais, a sudeste do Brasil (Fig. 1). A BHRJ vem sendo monitorada desde 2006 pelo setor de Engenharia de Água e Solo, da Universidade Federal de Lavras (UFLA) com apoio da Companhia Energética de Minas Gerais (CEMIG) e da Agência Nacional de Energia Elétrica (ANEEL). A ocupação da BHRJ é predominantemente rural e é uma bacia que apresenta características pedológicas, hidrológicas e de ocupação dos solos típicas da região onde está situada (Andrade et al., 2012).

A BHRJ possui uma área de drenagem de $33 \mathrm{~km}^{2} \mathrm{e}$ deságua diretamente no reservatório da Usina Hidrelétrica (UHE) de Camargos, pertencente a CEMIG. Diversos autores (Alves et al., 2019; Andrade et al., 2012; Beskow et al., 2011; Beskow et al., 2011) destacam que o comportamento dessa bacia é relevante na compreensão da dinâmica do ciclo hidrológico e no auxílio à tomada de decisões na região, no que diz respeito ao uso, conservação e preservação da qualidade dos recursos naturais, devido ao avançado estágio de degradação destes.

O clima na BHRJ, conforme a classificação Köppen, é do tipo Cwa e caracteriza-se por verões quentes e úmidos e invernos frios e secos, de modo que a temperatura média anual é de $19{ }^{\circ} \mathrm{C}$. A precipitação média anual é de $1500 \mathrm{~mm}$, sendo o período chuvoso compreendido no período de outubro a março e o período seco de abril a setembro (Fig. 2) (Alves et al., 2019; Andrade et al., 2012; Mello et al., 2012; Reboita et al., 2010). A região sofre influência de diferentes sistemas atmosféricos, sendo eles: Frentes frias, Zona de Convergência do Atlântico Sul (ZCAS) e formação local de nuvens convectivas Cumulonimbus (Reboita et al., 2010).

A bacia possui elevação média de 998 m e declividade média de $13 \%$. No que diz respeito ao uso e ocupação do solo, foram identificados por Alves et al. (2019) os seguintes usos na BHRJ: pastagem (38,5\%); culturas anuais, principalmente milho (Zea mays L.) e trigo (Triticum aestivum L.) (30,9\%); floresta nativa (15,1\%); eucalipto (Eucalyptus globulus) (10,3\%); solo nu (4,9\%) e área urbana (0,3\%). Além disso, Alves et al. (2019) identifi-

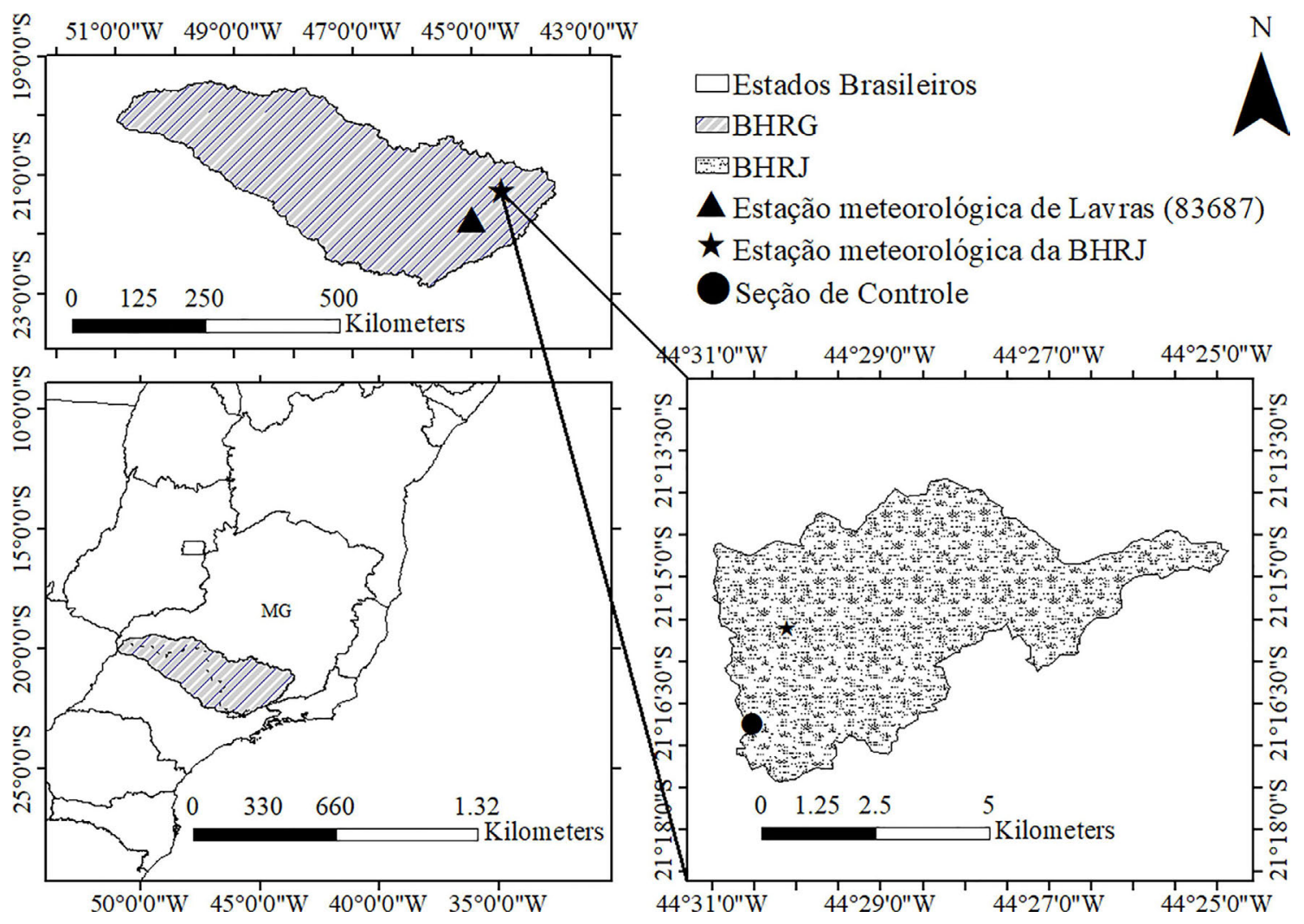

Figura 1 - Localização da Bacia Hidrográfica do Ribeirão Jaguara (BHRJ) no alto da Bacia Hidrográfica do Rio Grande (BHRG) no estado de Minas Gerais. 


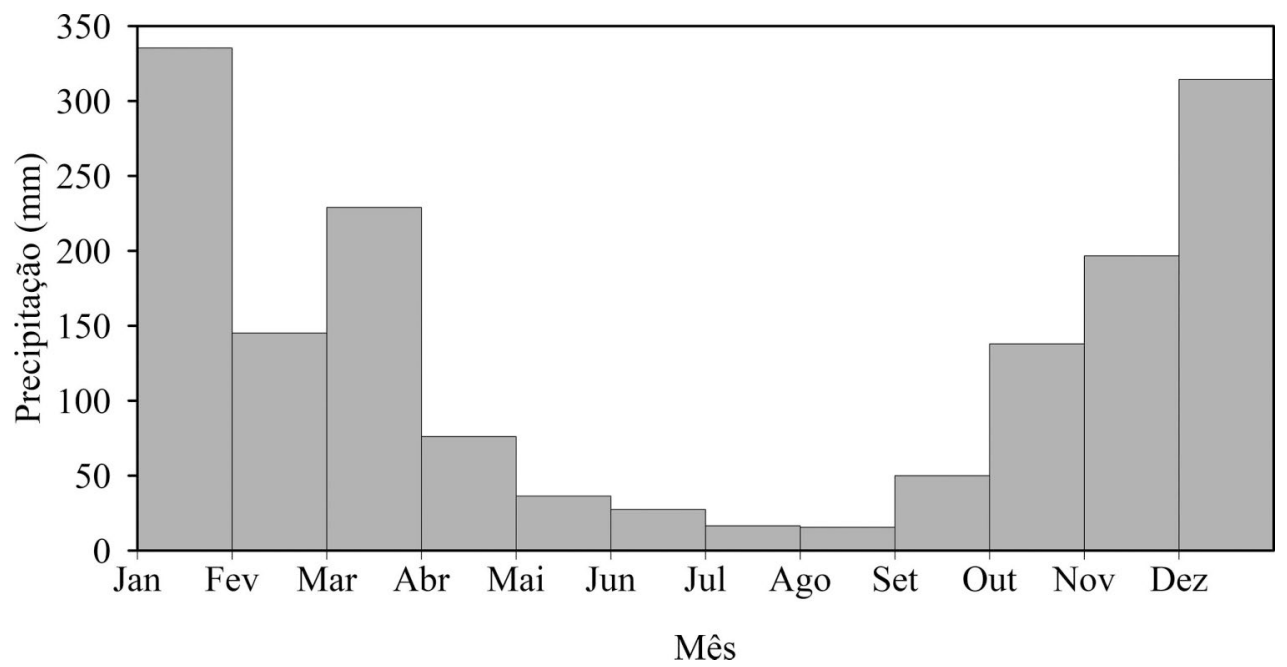

Figura 2 - Média da precipitação mensal na BHRJ para o período 2006-2014.

caram três classes principais de solos: Latossolos $(53,6 \%)$, Cambissolo háplico distrófico típico (19,3\%) e Neossolo flúvico $(27,1 \%)$.

\subsection{Modelo Hidrológico Distribuído (MHD-INPE)}

O Modelo Hidrológico Distribuído (MHD-INPE) (Rodriguez e Tomasella, 2016; Siqueira Júnior et al., 2015) foi desenvolvido pelo Instituto Nacional de Pesquisas Espaciais (INPE) a partir do Modelo de Grandes Bacias (Collischonn et al., 2007) do Instituto de Pesquisas Hidráulicas (MGB-IPH), o qual recebeu modificações nas rotinas para estimativa da evaporação e da separação de fluxos (Falck et al., 2015).

A separação dos fluxos estimada pelo MHD-INPE combina a formulação do modelo Xinanjiang (Zhao, 1992) e do modelo TopModel (Beven e Kirkby, 1979) para simular a resposta hidrológica. O procedimento de calibração do MHD-INPE é baseado no algoritmo do método de optimização Shuffled Complex Evolution (SCE-UA) (Duan et al., 1992).

A simulação da perda de água por interceptação ocorre por meio da metodologia proposta por Gash et al. (1995). A extração radicular profunda de captura da água da vegetação desde o solo é resolvida conforme o modelo de distribuição de raízes proposto por Jarvis (1989), de acordo com as estimativas de evaporação, obtidas diretamente no modelo hidrológico por meio do método de Penman-Monteith (Monteith, 1981). Os parâmetros calibráveis do MHD-INPE e suas respectivas unidades e intervalos de variação podem ser visualizados na Tabela 1.

A Tabela 2 sumariza alguns trabalhos que utilizaram o MHD-INPE, explicitando a área e localização da bacia hidrográfica, a resolução do modelo digital de elevação (MDE) e do terreno (MDT), a quantidade de estações meteorológicas e pluviométricas utilizadas, o período de calibração e validação do modelo e a aplicação desses tra-

Tabela 1 - Descrição dos parâmetros calibráveis do Modelo Hidrológico Distribuído (MHD-INPE), contendo suas respectivas unidades e intervalos de variação.

\begin{tabular}{|c|c|c|c|}
\hline Parâmetro & Unidade & Intervalo & Descrição \\
\hline$D_{1}$ & $\mathrm{~m}$ & $0-2$ & Espessura da camada superior \\
\hline$D_{2}$ & $\mathrm{~m}$ & $0-30$ & Espessura da camada intermediária \\
\hline$D_{3}$ & $\mathrm{~m}$ & $0-100$ & Espessura da camada inferior \\
\hline \multirow[t]{2}{*}{$K_{s s}$} & $\mathrm{~m} \mathrm{dia}^{-1}$ & $0,001-36$ & Multiplicador da condutividade hidráulica saturada \\
\hline & - & $1-10000$ & Coeficiente de anisotropia \\
\hline$T_{s u b}$ & $\mathrm{~m}^{2} \mathrm{dia}^{-1}$ & $0,01-100$ & Transmissividade máxima na camada inferior do solo \\
\hline \multirow[t]{2}{*}{$\xi$} & - & $0-1$ & $\begin{array}{l}\text { Razão do armazenamento na capacidade de campo e } S_{\max } \text { (valor máximo na célula no tempo } t \text { do armazenamento } \\
\text { na camada inferior do solo) }\end{array}$ \\
\hline & - & $0,01-4$ & $\begin{array}{l}\text { Parâmetro responsável por representar o retardamento da transmissividade em relação a espessura da zona satu- } \\
\text { rada }\end{array}$ \\
\hline$C_{\text {sub }}$ & $\operatorname{dia}^{-1}$ & $0,01-100$ & Parâmetro de roteamento para o fluxo superficial e subsuperficial \\
\hline$C_{\text {supe }}$ & $\operatorname{dia}^{-1}$ & $0,001-100$ & Parâmetro de roteamento para o fluxo base \\
\hline
\end{tabular}

Fonte: Manual de aplicação do MHD-INPE (2016). 
balhos. A escolha do MHD-INPE no presente estudo ocorreu mediante ao estudo realizado por Melo (2019) na Bacia Hidrográfica do Ribeirão Lavrinha (BHRL), a qual possui uma área de drenagem inferior $\left(6,7 \mathrm{~km}^{2}\right)$ a da BHRJ $\left(33 \mathrm{~km}^{2}\right)$, corroborando a possibilidade de aplicá-lo em uma bacia de pequeno porte.

\subsection{Dados de entrada e implementação do modelo hidrológico MHD-INPE}

O modelo hidrológico MHD-INPE foi implementado para a BHRJ, de modo que a bacia foi delimitada em células regulares com resolução espacial de $0,01^{\circ} \mathrm{x}$ $0,01^{\circ}$. Para a delimitação da BHRJ, foi utilizado o modelo digital de elevação (MDE) da missão Advanced Spaceborne Thermal Emission and Reflection Radiometer (ASTER), com resolução espacial de $30 \mathrm{~m}$ (Yamaguchi et al., 1998). A rede de drenagem de $30 \mathrm{~m}$ foi agregada a uma resolução de $0,01^{\circ}$ usando a direção predominante. Em seguida, a mesma foi comparada e aproximada a rede de drenagem da bacia fornecida pela plataforma do Insti- tuto Brasileiro de Geografia e Estatística (IBGE), a fim de efetuar eventuais correções no traçado obtido.

O modelo utiliza como entrada para a calibração dados de velocidade do vento, umidade relativa do ar, temperatura, pressão à superfície, radiação solar global e precipitação. Para isso, foi utilizada no período de 20062014 a série de dados meteorológicos diários da estação meteorológica localizada na BHRJ. A série de dados observados diários de vazão também foi utilizada para a análise de desempenho do modelo. Esta última foi obtida por meio de um linígrafo presente na seção de controle da BHRJ.

Os dados de solo foram extraídos do mapa de relevo (Fig. 3a) obtido pelo modelo normalizado de terrenos Height Above the Nearest Drainage (HAND) (Rennó et al., 2008). Assim como observado por Cuartas et al. (2012), o modelo HAND foi utilizado devido a indisponibilidade de mapas de solos detalhados para bacias de pequeno porte, como é o caso da BHRJ. Foram delimitadas três classificações para o relevo: áreas saturadas, intermediárias e não-saturadas. Na primeira classe, encontram-

Tabela 2 - Aplicações utilizando o modelo MHD-INPE em diferentes bacias hidrográficas.

\begin{tabular}{|c|c|c|c|c|c|c|}
\hline Pesquisa & Bacia hidrográfica & $\begin{array}{l}\text { MDE/MDT } \\
\text { (resolução) }\end{array}$ & Área & Medições da precipitação & Período & Aplicação do estudo \\
\hline $\begin{array}{l}\text { Falck et al. } \\
(2015)\end{array}$ & $\begin{array}{l}\text { Bacia Hidrográfica } \\
\text { do Rio Tocantins- } \\
\text { Araguaia }\end{array}$ & $\begin{array}{l}\text { MDE - } 90 \mathrm{~m} \\
\text { de resolução } \\
\text { espacial }\end{array}$ & $764.000 \mathrm{~km}^{2}$ & $\begin{array}{l}300 \text { estações pluviomé- } \\
\text { tricas }\end{array}$ & $\begin{array}{l}\text { Calibração } \\
(2000-2008) \text { e } \\
\text { Validação } \\
(2010-2011)\end{array}$ & $\begin{array}{l}\text { Avaliar a incerteza nas estimati- } \\
\text { vas de precipitação por satélite } \\
\text { e se estas podem ser utilizadas } \\
\text { como dados de entrada no } \\
\text { MHD-INPE. }\end{array}$ \\
\hline $\begin{array}{l}\text { Siqueira } \\
\text { Júnior et al. } \\
\text { (2015) }\end{array}$ & $\begin{array}{l}\text { Bacia Hidrográfica } \\
\text { do Rio Madeira }\end{array}$ & $\begin{array}{l}\text { MDE - } 90 \mathrm{~m} \\
\text { de resolução } \\
\text { espacial }\end{array}$ & $1.420 .000 \mathrm{~km}^{2}$ & $\begin{array}{l}4391 \text { estações pluviomé- } \\
\text { tricas }\end{array}$ & $\begin{array}{l}\text { Calibração e } \\
\text { Validação } \\
(1970-1990)\end{array}$ & $\begin{array}{l}\text { Impacto das mudanças climáti- } \\
\text { cas e das mudanças no uso e } \\
\text { ocupação do solo. }\end{array}$ \\
\hline $\begin{array}{l}\text { Mohor et al. } \\
\text { (2015) }\end{array}$ & $\begin{array}{l}\text { Bacia Hidrográfica } \\
\text { do Rio Tapajós }\end{array}$ & $\begin{array}{l}\text { MDE - } 90 \mathrm{~m} \\
\text { de resolução } \\
\text { espacial }\end{array}$ & $493.000 \mathrm{~km}^{2}$ & $\begin{array}{l}11 \text { estações meteor- } \\
\text { ológicas }\end{array}$ & $\begin{array}{l}\text { Calibração } \\
(1970-1990) \text { e } \\
\text { Validação } \\
(2003-2008)\end{array}$ & $\begin{array}{l}\text { Impacto das projeções climáti- } \\
\text { cas na bacia e na geração de } \\
\text { energia da UHE de Rio Pires. }\end{array}$ \\
\hline $\begin{array}{l}\text { Rodriguez e } \\
\text { Tomasella } \\
(2016)\end{array}$ & $\begin{array}{l}\text { Bacia Hidrográfica } \\
\text { Ji-Paraná }\end{array}$ & $\begin{array}{l}\text { MDE - } 90 \mathrm{~m} \\
\text { de resolução } \\
\text { espacial }\end{array}$ & $33.000 \mathrm{~km}^{2}$ & $\begin{array}{l}14 \text { estações pluviomé- } \\
\text { tricas }\end{array}$ & $\begin{array}{l}\text { Calibração } \\
(1996-2005) \text { e } \\
\text { Validação } \\
(1984-1995)\end{array}$ & $\begin{array}{l}\text { Analisar a capacidade do } \\
\text { MHD-INPE de simular os } \\
\text { impactos no uso e na mudança } \\
\text { da cobertura do solo }\end{array}$ \\
\hline $\begin{array}{l}\text { Casagrande } \\
\text { et al. }(2017)\end{array}$ & $\begin{array}{l}\text { Bacia Hidrográfica } \\
\text { do Rio Itajaí-Açu }\end{array}$ & $\begin{array}{l}\text { MDE - } 90 \mathrm{~m} \\
\text { de resolução } \\
\text { espacial }\end{array}$ & $15.500 \mathrm{~km}^{2}$ & $\begin{array}{l}68 \text { estações pluviomé- } \\
\text { tricas e uma estação me- } \\
\text { teorológica }\end{array}$ & $\begin{array}{l}\text { Calibração } \\
(1971-2009) \text { e } \\
\text { Validação } \\
(2010-2014)\end{array}$ & Alerta de cheias precoces \\
\hline $\begin{array}{l}\text { Tomasella } \\
\text { et al. }(2018)\end{array}$ & $\begin{array}{l}\text { Bacia Hidrográfica } \\
\text { do Rio Doce }\end{array}$ & $\begin{array}{l}\text { MDE - } 90 \mathrm{~m} \\
\text { de resolução } \\
\text { espacial }\end{array}$ & $83.400 \mathrm{~km}^{2}$ & $\begin{array}{l}262 \text { estações pluviomé- } \\
\text { tricas, sendo } 86 \text { dentro da } \\
\text { bacia, e } 24 \text { estações me- } \\
\text { teorológicas }\end{array}$ & $\begin{array}{l}\text { Calibração } \\
(2000-2009) \text { e } \\
\text { Validação } \\
(2009-2013)\end{array}$ & $\begin{array}{l}\text { Avaliar a probabilidade de } \\
\text { ocorrer inundações no período } \\
\text { de } 2001-2013 \text {. }\end{array}$ \\
\hline $\begin{array}{l}\text { Von Randow } \\
\text { et al. } 2019\end{array}$ & $\begin{array}{l}\text { Bacia Hidrográfica } \\
\text { do Rio Tocantins }\end{array}$ & $\begin{array}{l}\text { MDE - } 90 \mathrm{~m} \\
\text { de resolução } \\
\text { espacial }\end{array}$ & $960.000 \mathrm{~km}^{2}$ & $\begin{array}{l}\text { Nove estações de medi- } \\
\text { ção. }\end{array}$ & $\begin{array}{l}\text { Calibração } \\
(1970-1990) \text { e } \\
\text { Validação } \\
(1970-1990)\end{array}$ & $\begin{array}{l}\text { Impactos das mudanças climá- } \\
\text { ticas e das mudanças no uso e } \\
\text { ocupação do solo na vazão e na } \\
\text { geração de energia na bacia. }\end{array}$ \\
\hline Melo (2019) & $\begin{array}{l}\text { Bacia Hidrográfica } \\
\text { do Ribeirão Lavrinha }\end{array}$ & $\begin{array}{l}\text { MDT - } 30 \mathrm{~m} \\
\text { de resolução } \\
\text { espacial }\end{array}$ & $6,7 \mathrm{~km}^{2}$ & $\begin{array}{l}\text { Uma estação meteoro- } \\
\text { lógica. }\end{array}$ & $\begin{array}{l}\text { Calibração } \\
(2006-2008) \text { e } \\
\text { Validação } \\
(2008-2010)\end{array}$ & $\begin{array}{l}\text { Atuação do MHD-INPE na } \\
\text { microescala e em relação ao } \\
\text { modelo DHSVM. }\end{array}$ \\
\hline
\end{tabular}


(a)

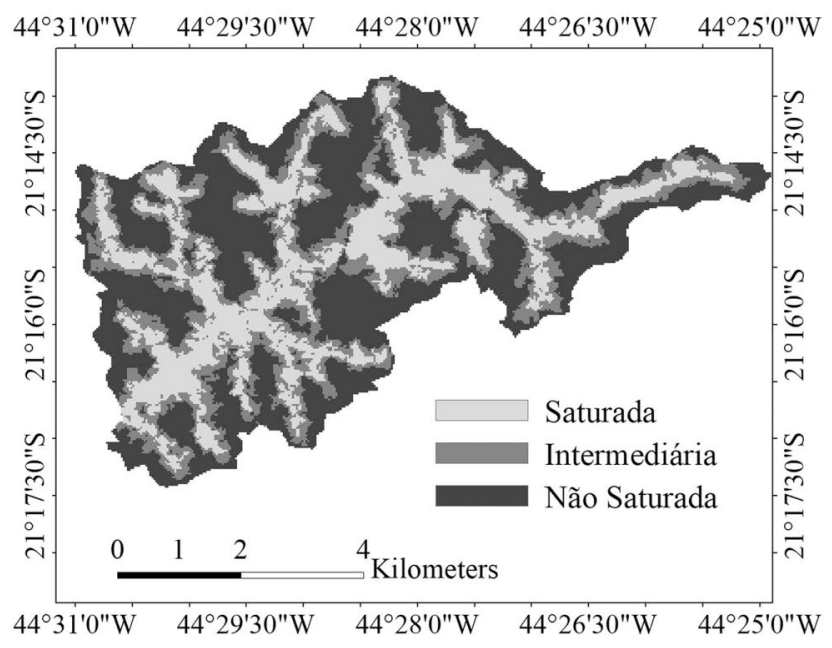

(b)

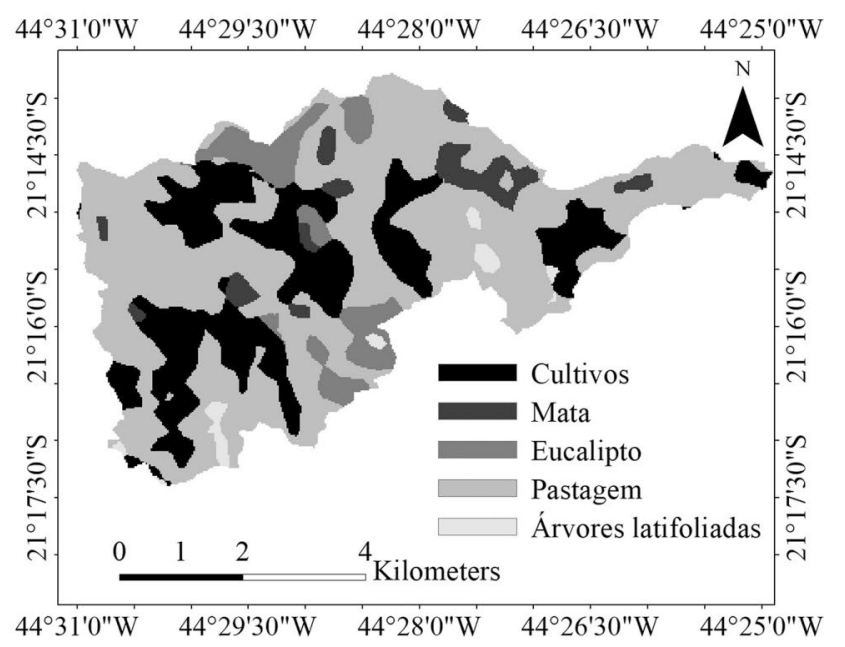

Figura 3 - Mapa do relevo obtido por meio do modelo HAND (a) e de uso e ocupação do solo (b) da BHRJ implementados no modelo MHD-INPE.

se os pontos que possuem de zero a cinco metros de altura em relação a rede de drenagem mais próxima - pontos estes correspondentes a vales, onde o lençol freático está mais próximo da superfície do solo (áreas saturadas). $\mathrm{Na}$ segunda classe, encontram-se os pontos que possuem de cinco a $20 \mathrm{~m}$ de altura em relação a rede de drenagem mais próxima - tais pontos correspondem a encostas (áreas intermediárias). A terceira classe são aquelas onde os pontos possuem de 20 a $100 \mathrm{~m}$ de altura em relação a rede de drenagem mais próxima - pontos que representam topo de morros (áreas não-saturadas).

Os dados de uso e ocupação do solo (Fig. 3b) foram extraídos das imagens fornecidas pela plataforma de pesquisa que disponibiliza dados raster e vetoriais produzidos pelo Laboratório de Processamento de Imagens e Geoprocessamento (LAPIG), da Universidade Federal de Goiás (UFG), com resolução espacial de $250 \mathrm{~m}$.

O mapa de relevo obtido pelo modelo $H A N D$ e o de uso e ocupação do solo foram agregados para a obtenção dos grupos de solo no MHD-INPE. Cada célula do modelo hidrológico considera as porcentagens de cada grupo de uso do solo contido dentro dessa célula. Ambos os mapas foram utilizados para definir o percentual de cada combinação de textura do solo, por meio do triângulo textural USDA, e do uso da terra em cada célula da grade de resolução de $0,01^{\circ}$ (Falck et al., 2015).

\subsection{Calibração, validação e análise de desempenho do MHD-INPE}

$\mathrm{O}$ aquecimento do modelo para homogeneização dos dados de entrada foi de 01 de janeiro a 31 de março de 2006. A calibração do modelo foi feita automaticamente, sendo o período de calibração de 01 de outubro de 2006 a 30 de setembro de 2012. O período de validação foi de 01 de outubro de 2012 a 30 de setembro de 2014.
Gerou-se e analisou-se as hidrógrafas diárias, com a finalidade de mostrar o ajuste da vazão simulada pelo modelo hidrológico em comparação a vazão observada na bacia hidrográfica. A análise do desempenho do modelo hidrológico MHD-INPE foi feita por meio do índice de eficiência Nash-Sutcliffe (NSE) (Nash e Sutcliffe, 1970), índice de eficiência Nash-Sutcliffe do logaritmo das vazões (LNSE), coeficiente de determinação $\left(\mathrm{R}^{2}\right)$ e porcentagem bias (PBIAS) (Yapo et al., 1996).

O NSE determina a habilidade do modelo em reproduzir a série de vazões observadas e possui uma forte influência das vazões máximas, enquanto o LNSE é mais sensível as vazões mínimas. Já o $\mathrm{R}^{2}$ informa sobre o grau de correlação entre os valores estimados e observados, além de relatar a habilidade do modelo em reproduzir a forma e a distribuição do hidrograma (Falck et al., 2015; Rodriguez e Tomasella, 2016). A porcentagem bias (PBIAS) avalia a tendência que a média dos valores simulados pelo modelo tem em relação aos observados na bacia hidrográfica (Brighenti., 2016; Yapo., 1996). A performance do modelo hidrológico foi classificada conforme a Tabela 3 (Moriasi et al., 2015).

\subsection{Projeções das mudanças climáticas}

As simulações e projeções climáticas diárias utilizadas no presente estudo foram regionalizas pelo modelo Eta. No Brasil, o modelo Eta foi instalado no CPTEC para previsões de curto prazo desde 1996 (Mesinger et al., 2012), para previsões sazonais desde 2002 (Chou et al., 2014a) e para auxiliar estudos relacionados a mudanças climáticas (Chou et al., 2014b), tendo como domínio a América do Sul e América Central (Martins et al., 2019). Conforme elencado por Chou et al. (2014a), este modelo usa a coordenada vertical Eta, que fica aproximadamente horizontal em áreas montanhosas e se torna uma vantagem 
Tabela 3 - Classificação dos índices estatísticos para avaliação do desempenho de modelos hidrológicos.

\begin{tabular}{lcccc}
\hline Índices Estatísticos & \multicolumn{2}{c}{ Intervalo de variação } & \multicolumn{2}{c}{ Critério de desempenho } \\
\cline { 3 - 5 } & & Muito Bom & Bom & Satisfatório \\
\hline NSE e LNSE & $-\infty$ a 1 & $>0,80$ & 0,70 a 0,80 & 0,50 a 0,70 \\
R $^{2}$ & 0 a 1 & $>0,85$ & 0,75 a 0,85 & 0,60 a 0,75 \\
PBIAS & $-\infty$ a 100 & $< \pm 5 \%$ & \pm 5 a $\pm 10 \%$ & \pm 10 a $\pm 15 \%$ \\
\hline
\end{tabular}

Fonte: Adaptado de Moriasi et al. (2015).

para estudos em regiões que possuem topografia íngreme. Além disso, o modelo foi montado com resolução espacial horizontal de $20 \mathrm{~km}$ e 38 níveis verticais, de modo que a parte superior é ajustada em $25 \mathrm{hPa}$.

No presente estudo foram consideradas previsões de três modelos e dois cenários do Quinto Relatório de Avaliação (AR5) do Painel Intergovernamental sobre Mudanças Climáticas (IPCC, 2013): os modelos climáticos globais (MCGs) HadGEM2-ES, MIROC5 e CanESM2 e os cenários RCP4.5 e RCP8.5. Esses modelos foram avaliados e selecionados, dentre os mais de 40 modelos climáticos disponibilizados pelo Coupled Model Intercomparison Project Phase 5 (CMIP5), por apresentarem melhor desempenho para simular o clima da América do Sul (Chou et al., 2014a, 2014b; Lyra et al., 2018). A respeito dos cenários de emissões, o RCP4.5 é o intermediário e representa um aquecimento global médio para o final do século XXI variando entre 1,1 e $2,6{ }^{\circ} \mathrm{C}$, enquanto o RCP8.5 representa o cenário mais pessimista e resulta num aquecimento médio variando entre 2,6 e $4,8{ }^{\circ} \mathrm{C}$ (Santos et al., 2019).

As simulações do clima presente (1961-2005) e as projeções do clima futuro (2006-2099) foram extraídas na Plataforma de Projeções de Mudança do Clima para a América do Sul regionalizadas pelo modelo Eta (PROJETA), do CPTEC, para o ponto de grade referente a localização da estação meteorológica da BHRJ.

Erros sistemáticos, comumente chamados de viés, são esperados das saídas de projeções de mudanças climáticas, uma vez que os processos atmosféricos que ocorrem nos modelos climáticos são aproximações daqueles que acontecem na atmosfera terrestre. No presente estudo, utilizou-se a metodologia proposta por Bárdossy e Pegram (2011) para corrigir erros sistemáticos das variáveis meteorológicas requeridas pelo modelo MHD-INPE. Nessa técnica, denominada percentil por percentil, são geradas funções de probabilidade cumulativas (FDPs) para cada variável meteorológica que será corrigida para o ponto de grade em questão e para todo o período de observação. Esse método assume que os erros sistemáticos são determinados pelo deslocamento das funções de distribuição de probabilidade para o mesmo nível de frequência experimental (Martins et al., 2019). As variáveis foram corrigidas, tanto para o clima presente (1961-2005) quanto para o clima futuro (2006-2099), utilizando-se a série histórica de dados meteorológicos observados de Lavras (código 83687), disponibilizada pelo Instituto Nacional de Meteorologia (INMET).

A utilização da série histórica de dados observados de Lavras foi necessária devido a série de dados advinda da estação meteorológica da BHRJ apresentar dados somente de 2006 a 2014. Portanto, a série não possui dados para equiparação com o clima presente dos modelos climáticos, que vai de 1961 a 2005. A comparação foi realizada entre as séries de precipitação e temperatura média de ambas as estações. Contudo, sabe-se que a precipitação é a variável que apresenta maior variabilidade espacial. A análise foi feita por meio da distribuição da frequência de excedência para o período de 2006 a 2014. Tal comparação possibilitou observar a semelhança no regime de chuvas entre as duas estações.

\subsection{Análise estatística de extremos e avaliação dos impactos de mudanças climáticas}

Após a calibração e validação do MHD-INPE na escala diária, foram utilizadas como entrada no modelo as simulações e projeções climáticas corrigidas. O modelo hidrológico foi executado para o clima presente (19612005) e para as projeções climáticas (2006-2099), sob cenários RCP4.5 e RCP8.5. Os cenários foram subdivididos em períodos de 30 anos (2006-2040, 2041-2070, 2071-2099), com a finalidade de avaliar o impacto das mudanças no clima na vazão futura da BHRJ ao longo do século XXI.

Após a simulação das vazões no MHD-INPE utilizando as projeções do modelo Eta como entrada, foi realizada a análise estatística de extremos (Ley et al., 2011), a qual está diretamente relacionada a curva de permanência das vazões simuladas para a BHRJ. A Tabela 4 explicita os descritores estatísticos utilizados no presente estudo, assim como o significado e sua respectiva equação.

$\mathrm{Na}$ etapa subsequente, aplicou-se o método de Budyko (1974), o qual relaciona o índice de aridez $(\varphi)$ à proporção que a evapotranspiração representa da precipitação. Por meio de uma relação física simples, a razão entre a evapotranspiração real $\left(E T_{R}\right)$ e a precipitação $(P R E C)$ pode ser determinada por meio da relação entre evapotranspiração potencial $\left(E T_{P}\right)$ e a precipitação. O balanço hídrico na bacia hidrográfica é descrito conforme a Eq. (1) (Oliveira et al., 2019): 
Tabela 4 - Descritores estatísticos utilizados na vazão simulada pelo MHD-INPE.

\begin{tabular}{|c|c|c|}
\hline Descritor & Descrição & Equação \\
\hline SEASON & Diferença entre as vazões dos períodos sazonais de cheia (verão) e seca (inverno). & $\mathrm{SEASON}=\frac{\text { médiaCheia }- \text { médiaSeca }}{\text { média }}$ \\
\hline $\mathrm{Q}_{\mathrm{SM}}$ & $\begin{array}{l}\text { Declividade da curva de permanência nas vazões intermediárias. Indica a variabilidade } \\
\text { média dos coeficientes de vazão. }\end{array}$ & $\mathrm{Q}_{\mathrm{SM}}=\frac{\text { quantill }, 8-\text { quantil0,2 }}{\text { média }}$ \\
\hline MWH & $\begin{array}{l}\text { Segmentos de vazões máximas que indica a resposta hidrológica para altos índices } \\
\text { pluviométricos. }\end{array}$ & $\begin{array}{c}\mathrm{MWH}=\frac{\sum_{\mathrm{h}=1} \mathrm{Q}_{\mathrm{h}}}{\mathrm{H}} \\
\mathrm{h}=1,2, \ldots H \text { vazões com probabilidade de exce- } \\
\text { dência }<0,05 .\end{array}$ \\
\hline MWL & $\begin{array}{l}\text { Segmentos de vazões mínimas que indica a resposta hidrológica para baixos índices } \\
\text { pluviométricos. }\end{array}$ & $\begin{array}{c}\mathrm{MWL}=\frac{\sum_{\mathrm{L}=1}^{\mathrm{L}} \mathrm{Q}_{1}}{\mathrm{~L}} \\
1=1,2, \ldots L \text { vazões com probabilidade de exce- } \\
\text { dência }>0,95 .\end{array}$ \\
\hline
\end{tabular}

Fonte: Adaptado de Ley et al. (2011), Siqueira Júnior et al. (2015) e Lopes et al. (2017).

\section{Resultados e Discussão}

$$
P R E C=E T_{R}+Q+\frac{\Delta S}{\Delta t}
$$

onde $P R E C$ é a precipitação, $E T_{R}$ é a evapotranspiração real, $Q$ é a vazão e $\Delta S / \Delta t$ é a variação do armazenamento de água na bacia hidrográfica ao longo do tempo.

No método de Budyko, os fatores climáticos precipitação $(P R E C)$ e evapotranspiração potencial $\left(E T_{P}\right)$ são os principais reguladores do balanço hídrico, assumindo a escala média anual. Considerando períodos longos $(>10$ anos), a variação do armazenamento de água $(\Delta S / \Delta t)$ no balanço hídrico não é significativa e, portanto, a média anual da evapotranspiração real $\left(E T_{R}\right)($ Eq. (2)) pode ser obtida por meio da diferença entre a precipitação (PREC) e a vazão $(Q)$, ambas em mm. A fração da precipitação (PREC) na evapotranspiração real $\left(E T_{R}\right)$ e na vazão $(Q)$ é dada pelo índice de evaporação $(\varepsilon)($ Eq. (3)):

$$
\begin{gathered}
E T_{R}=\text { PREC }-Q \\
\varepsilon=\left[\varphi \cdot \tanh \left(\varphi^{-1}\right) \cdot(1-\exp (-\varphi))\right]^{0,5}
\end{gathered}
$$

onde $\varphi$ (índice de aridez) é a razão entre a evapotranspiração potencial média $\left(E T_{P}\right)$ e a precipitação média (PREC).

No presente estudo, o índice $\varphi$ e $\varepsilon$ foram calculados para o clima presente (1961-2005) e clima futuro (20062040, 2041-2070 e 2071-2099), sob os cenários RCP4.5 e RCP8.5 dos modelos climáticos. Por meio da relação entre os índices, conclui-se que dois fatores podem estar limitando a evapotranspiração na bacia: o fornecimento de água, quando $\varphi>1$ e o fornecimento de energia, quando $\varphi<1$ (Oliveira et al., 2019).

\subsection{Calibração e aplicação do modelo hidrológico}

O modelo hidrológico MHD-INPE foi calibrado e validado no passo de tempo diário. O passo de tempo diário foi adotado em decorrência da incompatibilidade das projeções climáticas horárias com a metodologia percentil por percentil adotada na correção de erros sistemáticos.

A vazão observada e a vazão simulada pelo MHDINPE na BHRJ podem ser visualizadas na Fig. 4. As hidrógrafas foram subdividas conforme os períodos (calibração e validação) para o passo de tempo diário. É importante ressaltar a dificuldade do modelo em representar os picos de vazão, o que pode ser consequência da baixa disponibilidade de dados pluviométricos espacializados na área de estudo, bem como das limitações de dados de entrada para o modelo, conforme observado em estudos anteriores utilizando o MHD-INPE (Falck et al., 2015; Rodriguez e Tomasella, 2016). Além disso, percebeu-se, por meio das hidrógrafas, que o modelo mostrou dificuldade ao representar o decaimento da curva de recessão, simulando, assim, um volume menor nesses períodos quando comparada a série observada, o que também foi observado por Neto et al. (2014) ao aplicar o modelo SWAT na BHRJ.

As estatísticas de precisão utilizadas para a análise de desempenho do modelo MHD-INPE na estimativa da vazão na BHRJ foram apresentadas na Tabela 5. Os valores de NSE foram superiores a 0,700, tanto para a calibração quanto para a validação. Já os valores de LNSE foram inferiores a 0,700 , o que implica uma maior dificuldade nas simulações das vazões mínimas, principalmente no passo de tempo diário. Isso pode ser resultado da dificuldade do modelo em representar a resposta hidrológica no passo de tempo diário em bacias de pequeno porte (Casagrande et al., 2017; Falck et al., 2015; Siqueira Júnior et al., 2015). 
(a)

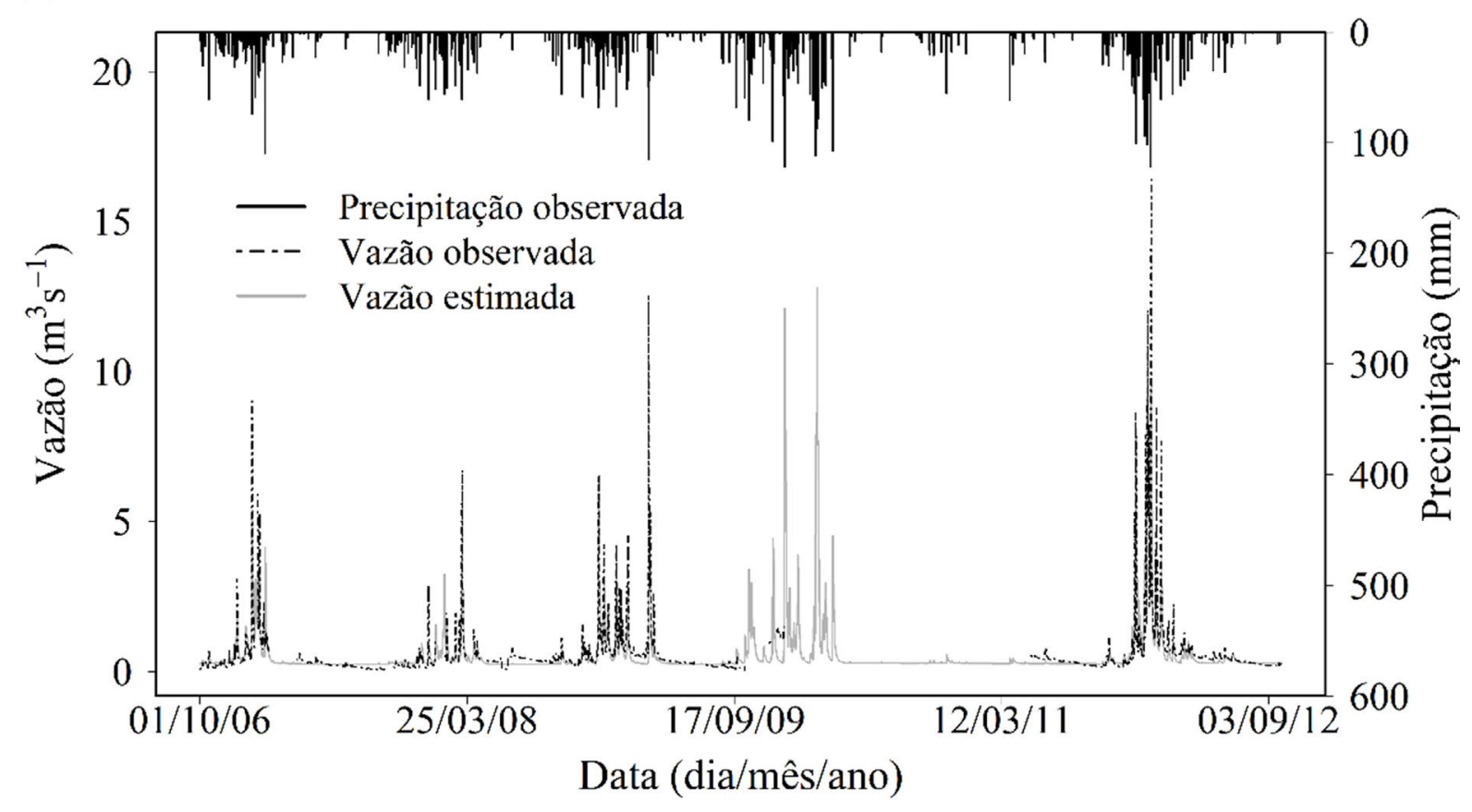

(b)

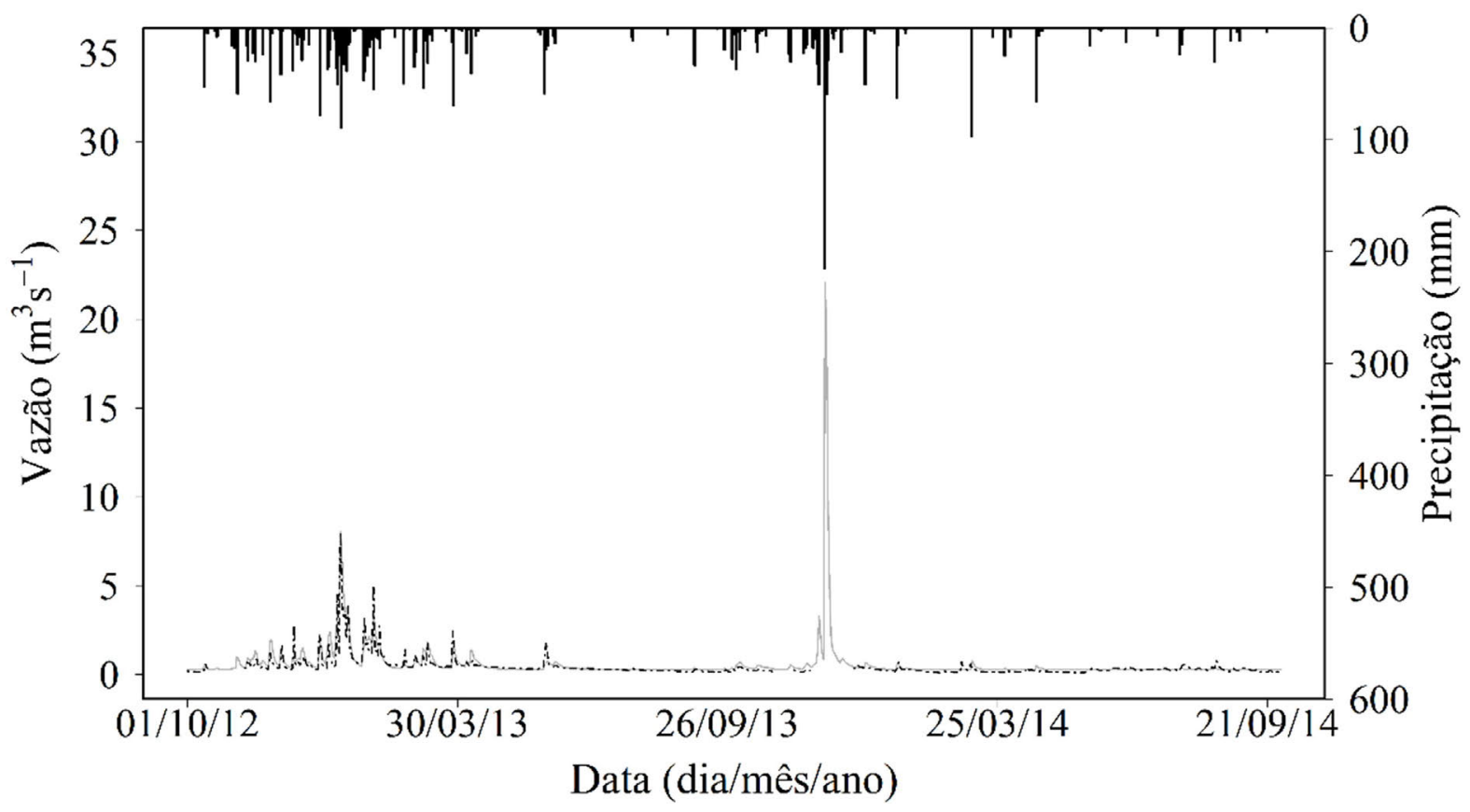

Figura 4 - Hidrógrafas para o período de calibração (out/2006 - set/2012) (a) e validação (out/2012 - set/2014) (b) do modelo MHD-INPE no passo de tempo diário.

Tabela 5 - Índices estatísticos obtidos para a calibração (out/2006 - set/2012) e validação (out/2012-set/2014) do modelo MHD - INPE no passo de tempo diário.

\begin{tabular}{lcccc}
\hline Período & NSE & LNSE & R $^{2}$ & PBIAS (\%) \\
\hline Calibração & 0,742 & 0,622 & 0,748 & $-9,9$ \\
Validação & 0,715 & 0,529 & 0,784 & 21,6 \\
\hline
\end{tabular}


O PBIAS de $-9,9 \%$ na calibração, apesar de satisfatório, indica subestimação da vazão nesse período. Quanto ao período da validação, o PBIAS mostrou desempenho não satisfatório (Moriasi et al., 2015) ao superestimar a vazão da BHRJ. O $\mathrm{R}^{2}$ foi superior a 0,700 tanto na calibração quanto na validação. O desempenho do MHDINPE foi, em geral, satisfatório, conforme a classificação dos índices estatísticos proposta por Moriasi et al. (2015).

Vale mencionar, ainda, a excepcional seca que atingiu a região sudeste do Brasil no ano hidrológico de 20132014, o qual está incluso no período da validação. Esse fenômeno climático fez com que o período da validação apresentasse condições muito diferentes do período da calibração, situação esta que afeta o desempenho de qualquer modelo hidrológico.

\subsection{Projeções climáticas corrigidas e vazão simulada pelo MHD-INPE}

Comparando-se as simulações climáticas dos modelos atmosféricos (Eta-HadGEM2-ES, Eta-MIROC5 e EtaCanESM2) para o clima presente (1961-2005) e as observações da estação meteorológica de Lavras para o mesmo período, verificou-se uma grande diferença entre os dados, indicando a necessidade de realizar a correção de erros sistemáticos dessas simulações, tanto do clima presente quanto do clima futuro (2006-2040, 2041-2070 e 20712099), antes destas serem utilizadas como entrada no MHD-INPE. Todas as variáveis meteorológicas requeridas pelo MHD-INPE foram corrigidas (Zákhia et al., 2020), com ênfase para a precipitação e a temperatura média, variáveis essenciais em estudos hidrológicos e amplamente utilizadas para avaliar a tendência de mudanças climáticas (Asfaw et al., 2018).

De modo geral, todos os modelos climáticos preveem aumentos da temperatura média (anual, mensal e sazonal) para a área investigada ao longo do século XXI, sob os cenários RCP4.5 e RCP8.5. A direção da tendência da precipitação não é a mesma para todos os modelos climáticos. Embora os resultados mostrem variabilidade entre os modelos, os cenários indicaram consenso na redução da precipitação nos meses iniciais do ano hidrológico (outubro a dezembro) e na maioria das estações do ano, com exceção apenas do inverno (Zákhia et al., 2020).

A vazão foi simulada no MHD-INPE utilizando como entrada as simulações climáticas corrigidas e os dados meteorológicos da estação de Lavras/INMET, para fins de comparação. Esta última foi utilizada como vazão de referência.

A Fig. 5 mostra os descritores estatísticos da curva de permanência das vazões diárias simuladas pelo MHDINPE utilizando como entrada os dados meteorológicos de referência e as simulações do modelo Eta para o único ponto de grade da BHRJ no clima presente (1961-2005). De modo geral, os descritores da curva de permanência das vazões obtidas por meio das simulações do modelo

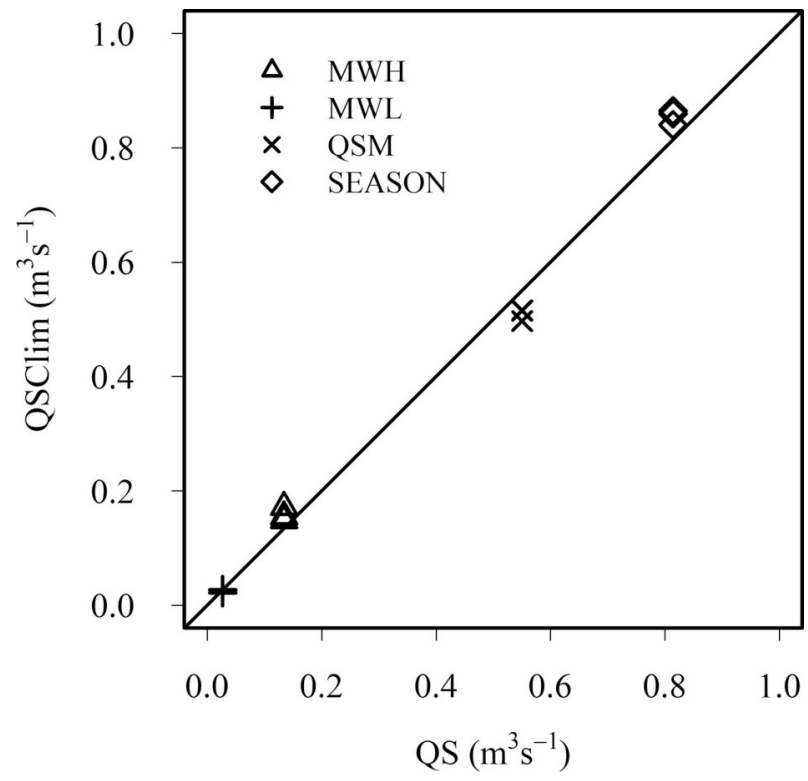

Figura 5 - Comparação entre os descritores da curva de permanência (MWH, MWL, QSM e SEASON) da vazão simulada pelo MHD-INPE utilizando como entrada os dados meteorológicos de Lavras/INMET (QS) e as projeções do modelo atmosférico Eta (QSClim) para a BHRJ, no período de 1961-2005.

Eta mostraram uma estreita aproximação aos descritores oriundos dos dados de referência. É possível observar maiores diferenças na inclinação do segmento médio $\left(\mathrm{Q}_{\mathrm{SM}}\right)$ da curva de permanência, de modo que as simulações subestimaram o valor em relação aos dados de referência. O mesmo aconteceu com o segmento de vazões máximas $(\mathrm{MWH})$ e o indicador de sazonalidade (SEASON), nesse caso, apontando superestimação das vazões obtidas por meio das simulações climáticas.

A variabilidade percentual entre os descritores estatísticos ( $\mathrm{Q}_{\mathrm{SM}}$, SEASON, MWH e MWL) da curva de permanência das vazões simuladas pode ser verificada na Fig. 6. O modelo Eta-MIROC5 mostrou um aumento na inclinação do segmento médio $\left(\mathrm{Q}_{\mathrm{SM}}\right)$, exceto no cenário RCP8.5 do período de 2006-2040. O aumento da $\mathrm{Q}_{\mathrm{SM}}$ também pode ser observado no mesmo cenário do período de 2071-2099 do modelo Eta-CanESM2. Entretanto, de modo geral, os modelos Eta-HadGEM2-ES e EtaCanESM2 indicaram redução da $\mathrm{Q}_{\mathrm{SM}}$, chegando a uma redução de até $43,22 \%$ com o modelo Eta-CanESM2, no cenário RCP8.5, período de 2041-2070.

O segmento médio da curva de permanência das vazões $\left(Q_{S M}\right)$ (Fig. 6a) está associado a vazões advindas de chuvas moderadas e ao retardamento da resposta do fluxo base a médio prazo, além de representar a variabilidade do segmento médio dos coeficientes de escoamento (Ley et al., 2011; Siqueira Júnior., 2015). Isso significa que quando a curva de permanência apresenta inclinações menos íngremes, observa-se uma redução das respostas das vazões a precipitação (Ley et al., 2011; Siqueira 
(a)

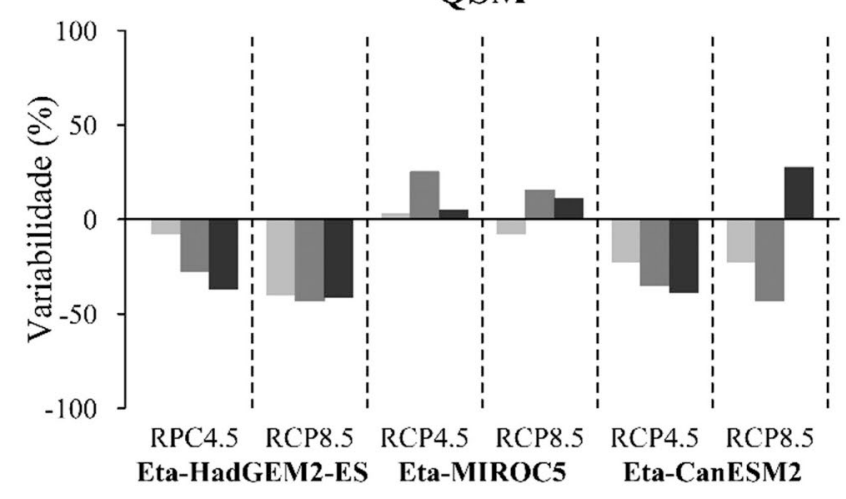

(b)

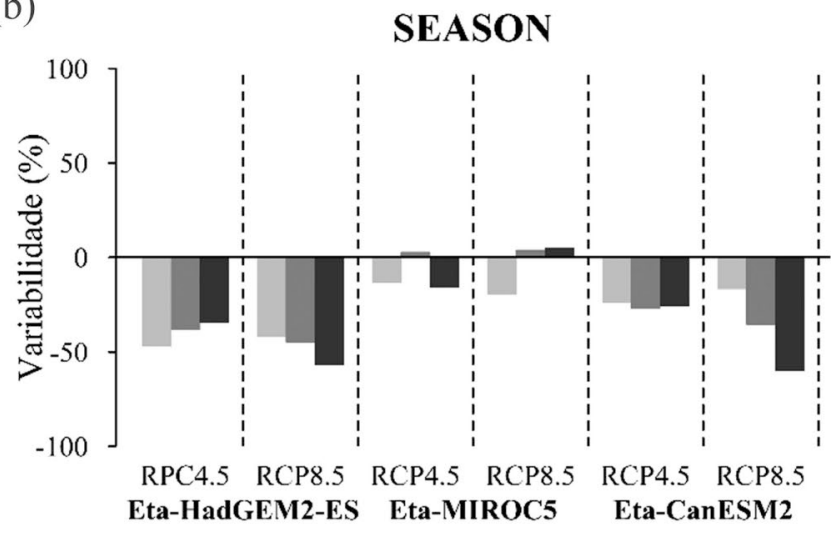

(c)

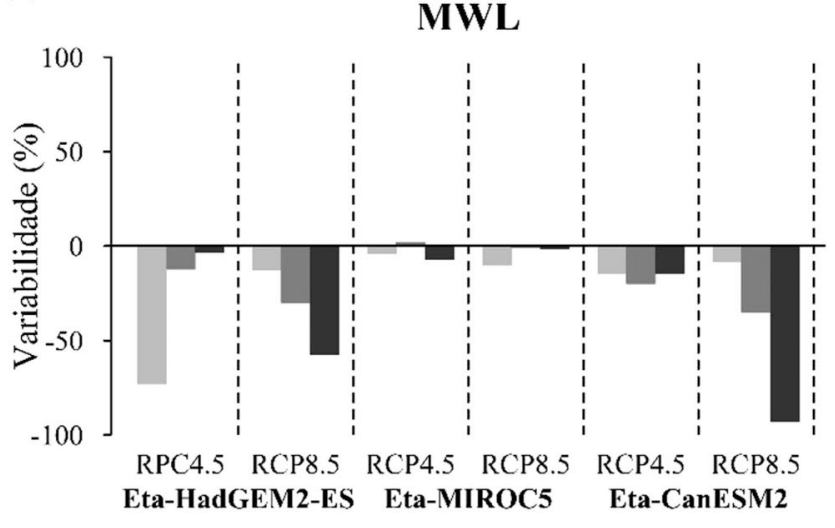

(d)

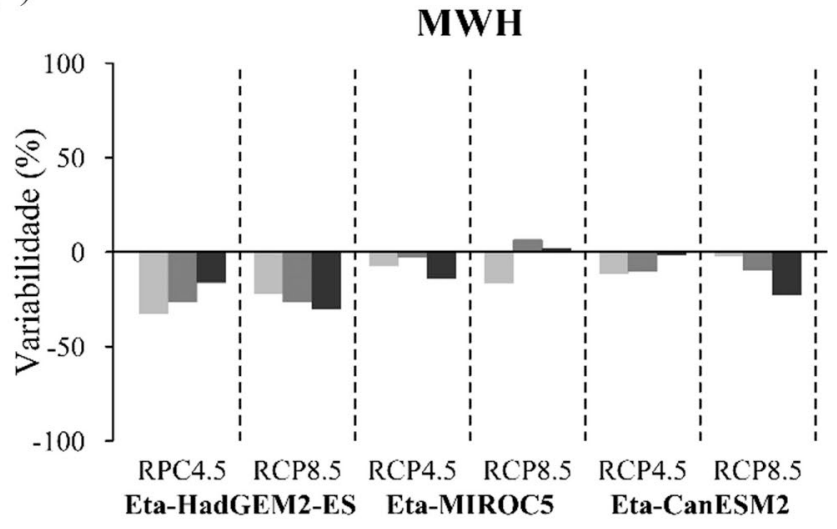

\section{$2006-2040$ - 2041-2070 - 2071-2099}

Figura 6 - Variabilidade (\%) entre os descritores estatísticos da curva de permanência das vazões simuladas pelo MHD-INPE utilizando as projeções futuras (2006-2040, 2041-2070 e 2071-2099), nos cenários RCP4.5 e RCP8.5, e as projeções do clima presente (1961-2005) dos modelos Eta-HadGEM2ES, Eta-MIROC5 e EtaCanESM2.

Júnior., 2015) que são uma resposta ao aumento da variabilidade das chuvas intrasazonais, afetando, assim, o escoamento no curso d'água, conforme observado, por exemplo, no cenário RCP8.5 do modelo Eta-CanESM2, no período de 2041-2070.

No que diz respeito ao descritor que expressa as diferenças entre as vazões das estações seca (abril a setembro) e chuvosa (outubro a março) (SEASON) (Fig. 6b), foi possível observar uma redução da sazonalidade na maioria das projeções avaliadas. O modelo Eta-MIROC5 apresentou aumentos não expressivos no período de 20412070 (RCP4.5 e RCP8.5) e 2071-2099 (RCP8.5). Essa redução predominante do descritor SEASON pode ser resultado da combinação entre a grande área de pastagem presente na BHRJ e a evidente redução da precipitação (Zákhia et al., 2020) projetada no clima futuro. Essa combinação, consequentemente, reduz a evapotranspiração e a variabilidade sazonal da umidade do solo (Siqueira Júnior., 2015).
Quanto ao segmento de vazões mínimas (Fig. 6c), indicado pelo MWL, todas as projeções mostraram uma consistente redução das vazões mínimas, as quais são importantes por serem consideradas como referência em processos envolvendo gestão de recursos hídricos. Essa redução foi mais significante pelas projeções dos modelos Eta-HadGEM2-ES (cenários RCP4.5 e RCP8.5) e EtaCanESM2 (cenário RCP8.5), mas não em todos os períodos das projeções, chegando a reduzir até $92,97 \%$ no período de 2071-2099 do cenário RCP8.5 nas projeções do modelo Eta-CanESM2.

O descritor referente aos segmentos de vazões de pico (MWH) (Fig. 6d) indicou, de modo geral, redução das vazões máximas por meio das projeções climáticas na BHRJ, exceto no cenário RCP8.5 nas projeções do modelo Eta-MIROC5. No entanto, a redução mostrou-se mais acentuada nas projeções do modelo Eta-HadGEM2-ES, reduzindo até $32,7 \%$ no período de $2006-2040$ no cenário RCP4.5. 
Vale mencionar que apesar da proximidade dos descritores da curva de permanência da vazão simulada pelos modelos climáticos aos da vazão simulada mantida como referência, a diferença entre eles não é incomum. Oliveira et al. (2017) destacaram que as incertezas relacionadas às estruturas dos modelos climáticos, ao forçamento radiativo dos cenários, a parametrização do modelo hidrológico, a redução de escala (downscaling) e a correção de erros sistemáticos devem ser consideradas.

Essas incertezas, no entanto, apresentam pesos diferentes na obtenção do resultado final em estudos envolvendo impactos de mudanças climáticas. Conforme destacado também por Amorim e Chaffe (2019a, 2019b), as incertezas advindas da modelagem hidrológica são usualmente menores do que aquelas referentes aos modelos climáticos e a técnicas regionalização.

As pesquisas de Amorim e Chaffe (2019a, 2019b) também reportam que ao indicar as fontes de incertezas individualmente, a regionalização e a correção de erros sistemáticos são consideradas os fatores mais limitantes. A técnica percentil por percentil, a qual foi abordada no presente estudo, é uma das mais utilizadas em diversos estudos envolvendo mudanças climáticas no Brasil na última década, mostrando-se sofisticada e confiável para fornecer projeções corrigidas (Amorim e Chaffe, 2019b). Apesar dos bons resultados obtidos com essa técnica, problemas podem ser encontrados quando a "cauda" da distribuição estatística utilizada é distorcida, fazendo com que eventos extremos pareçam deturpados, e, também, por não considerar diretamente estatísticas que são dependentes do tempo, como dias secos consecutivos (Amorim e Chaffe, 2019b).

Ademais, a limitação referente a regionalização das projeções climáticas de MCGs ficou evidente no presente estudo. A resolução horizontal do modelo Eta $(20 \times$ $20 \mathrm{~km}$ ) não foi capaz de distribuir totalmente o regime de chuvas de uma bacia hidrográfica de pequeno porte como a BHRJ $\left(33 \mathrm{~km}^{2}\right)$. Tal situação também foi observada por Lyra et al. (2018), ao comparar as projeções climáticas do modelo Eta com resolução horizontal de 5 e $20 \mathrm{~km}$, para o RCP4.5 e RCP8.5, em diferentes localidades, onde foi possível notar melhor ajuste utilizando-se projeções climáticas de maior resolução espacial $(5 \mathrm{~km})$. No entanto, Amorim e Chaffe (2019b) destacam que o procedimento de modelagem adotado deve ser individual, ou seja, a avaliação e a aplicação devem ser baseadas nas necessidades dos usuários, ao invés de, por exemplo, procurar pela mais alta resolução das projeções climáticas.

As trajetórias temporais da dispersão do índice de evaporação $(\varepsilon)$ em relação ao índice de aridez $(\varphi)$, obtidos por meio das simulações do MHD-INPE utilizando as projeções do modelo Eta como entrada está na Fig. 7. O método de Budyko foi aplicado ao clima presente (CP), que é o período compreendido entre 1961-2005, e o clima futuro, o qual foi subdivido em T1 (2006-2040), T2 (20412070) e T3 (2071-2099), sob os cenários RCP4.5 (Fig. 7a) e RCP8.5 (Fig. 7b).

O índice de aridez para o clima presente $(0,80)$ das simulações do modelo Eta indicou que a evapotranspiração na BHRJ foi limitada pela energia disponível nesse período. Comparando-se o clima presente $(\mathrm{CP})$ com o clima futuro (T1, T2, T3) do Eta-HadGEM2-ES, os valores de $\varphi$ foram maiores que um, o que implica em aumento da aridez na BHRJ, visto que a evapotranspiração passou a ser limitada pelo abastecimento de água. Por meio das projeções do Eta-MIROC5, observou-se que os índices de aridez variaram no clima futuro (T1, T2 e T3) em relação ao clima presente (1961-2005), no entanto, os valores mostraram consenso e permaneceram abaixo de um, o que implica limitação pela energia disponível até o final do século, em ambos os cenários. (a)

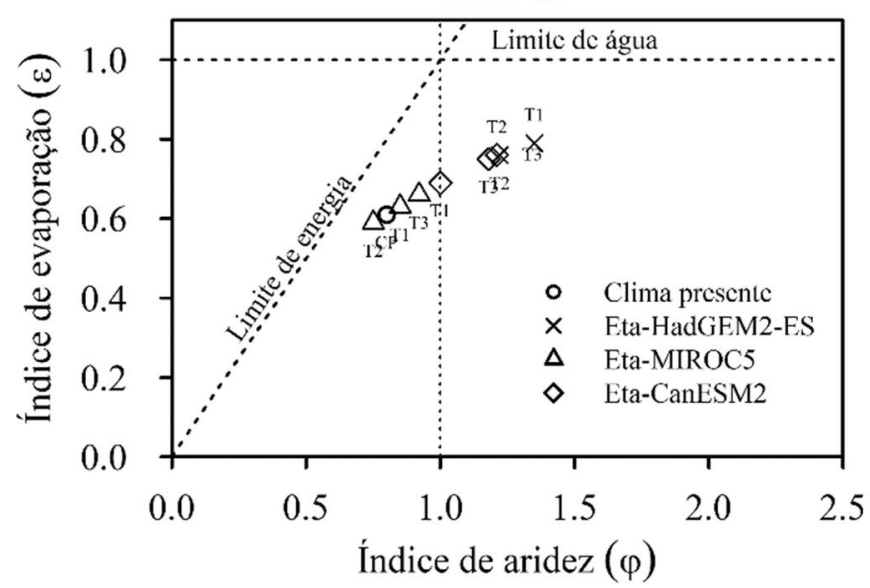

(b)

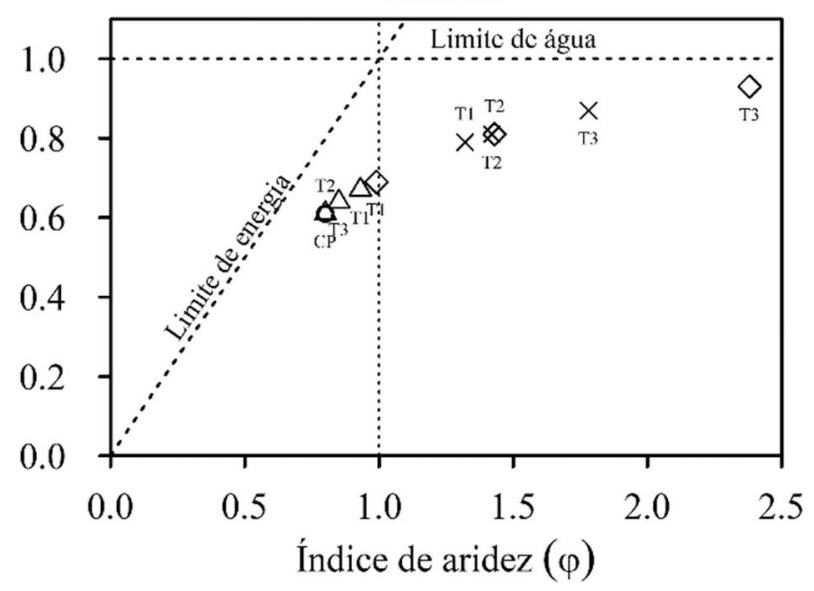

Figura 7 - Trajetórias temporais da dispersão de $\varepsilon$ (ETR/PREC) versus $\varphi$ (ETP/PREC) ao longo da curva de Budyko para o RCP4.5 (a) e RCP8.5 (b) dos modelos Eta-HadGEM2-ES, Eta-MIROC5 e Eta-CanESM2. 
O Eta-CanESM2 não mostrou consenso como os outros modelos climáticos, mostrando maiores variações no clima futuro quando comparado ao clima presente. Os índices de aridez do período de T1 (2006-2040) foram 1,00 e 0,99 , para o RCP4.5 e o RCP8.5, respectivamente. Nos demais períodos (T2 e T3), os valores de $\varphi$ foram superiores a um em ambos os cenários climáticos, mostrando mudança em relação ao clima presente ao destacar a limitação da evapotranspiração pelo fornecimento de água.

Dessa forma, é possível observar que a avaliação do índice de aridez na BHRJ sugere um risco de escassez hídrica no clima futuro (2006-2040, 2041-2070 e 20712099). A limitação da evapotranspiração pelo abastecimento de água $(\varphi>1)$ foi evidenciada por meio das projeções dos modelos Eta-HadGEM2-ES e Eta-CanESM2 e pode afetar diretamente o consumo humano, a geração de energia hidrelétrica e agricultura na bacia até o final do século XXI, assim como observado por Alvarenga et al. (2018).

\section{Considerações Finais}

- O modelo hidrológico MHD-INPE representou de forma satisfatória a BHRJ, de acordo com os índices estatísticos aplicados na análise de desempenho do modelo. Dessa forma, o modelo mostrou-se apto para simular a vazão futura na bacia por meio das projeções climáticas do modelo Eta;

- De modo geral, os descritores estatísticos da curva de permanência das simulações do modelo Eta mostraram um bom desempenho do MHD-INPE na simulação do clima presente (1961-2005), ou seja, as simulações do clima presente associadas a correção de erros sistemáticos representaram a hidrologia da bacia no mesmo período;

- Ressalta-se ainda que a inclinação do segmento médio $\left(\mathrm{Q}_{\mathrm{SM}}\right)$ não apresentou consenso com as projeções climáticas do modelo Eta no futuro, para ambos os cenários climáticos. Quanto a diferença entre as vazões das estações seca e chuvosa (SEASON), o segmento de vazões mínimas (MWL) e o segmento de vazões máximas (MWH) foi possível observar, em geral, uma redução em todas as projeções avaliadas ao longo do século XXI, nos cenários RCP4.5 e RCP8.5;

- O conjunto de modelos climáticos mostraram-se coerentes quanto a redução da vazão sazonal média no clima futuro (2006-2040, 2041-2070 e 2071-2099), tanto no RCP4.5 quanto no RCP8.5, em todas as estações do ano. As maiores reduções da vazão simulada foram verificadas no verão $(35,1 \%)$, assim como na precipitação total média sazonal, ambas no RCP8.5 do período de 2071-2099;

- Analisando-se a curva de Budyko, os modelos EtaHadGEM2-ES e Eta-CanESM2 mostraram risco de escassez hídrica na BHRJ no futuro ao limitarem a evapotranspiração pelo fornecimento de água.

Caso as projeções climáticas se concretizem até o final do século, é possível que haja queda ou, até mesmo, inviabilização da produtividade de pequenos agricultores que habitam a região da BHRJ, principalmente, de milho, visto que a safra no estado de Minas Gerais ocorre no período (outubro - janeiro) em que se observou elevada redução da precipitação e da vazão ao longo das análises. Além disso, do ponto de vista do ciclo hidrológico, o constante aumento da temperatura ao longo do século faz com que as taxas de evaporação também aumentem, elevando os níveis de vapor d'água na atmosfera e deixando a disponibilidade hídrica imprevisível para a região.

\section{Agradecimentos}

Os autores gostariam de agradecer a Coordenação de Aperfeiçoamento de Pessoal de Nível Superior (CAPES) e o Conselho Nacional de Desenvolvimento Científico e Tecnológico (CNPq - processo: 429247/2018-4) pelo financiamento dessa pesquisa.

\section{Referências}

ALVARENGA, L.A.; DE MELLO, C.R.; COLOMBO, A.; CHOU, S.C.; CUARTAS, L.A.; VIOLA, M.R. Impacts of climate change on the hydrology of a small brazilian headwater catchment using the Distributed Hydrology-SoilVegetation Model. American Journal of Climate Change, v. 7, n. 2, p. 355-366, 2018.

ALVES, G.J.; DE MELLO, C.R.; BESKOW, S.; JUNQUEIRA, J.A.; NEARING, M.A. Assessment of the soil conservation service-curve number method performance in a tropical oxisol watershed. Journal of Soil and Water Conservation, v. 74, n. 5, p. 500-512, 2019.

AMORIM, P.B.; CHAFFE, P.L.B. Towards a comprehensive characterization of evidence in synthesis assessments: the climate change impacts on the Brazilian water resources. Climatic Change, v. 155, n. 1, p. 37-57, 2019a.

AMORIM, P.B.; CHAFFE, P.L.B. Integrating climate models into hydrological modelling: What's going on in Brazil? Revista Brasileira de Recursos Hidricos, v. 24, p. 1-17, 2019b.

ANDRADE, M.A.; MELLO, C.R.; BESKOW, S. Hydrological simulation in a watershed with predominance of Oxisol in the upper Grande river region, MG - Brazil. Revista Brasileira de Engenharia Agrícola e Ambiental, v. 17, n. 1, p. 69-76, 2012.

ASFAW, A.; SIMANE, B.; HASSEN, A.; BANTIDER, A. Variability and time series trend analysis of rainfall and temperature in northcentral Ethiopia: A case study in Woleka sub-basin. Weather and Climate Extremes, v. 19, p. 29-41, 2018.

BÁRDOSSY, A.; PEGRAM, G. Downscaling precipitation using regional climate models and circulation patterns toward hydrology. Water Resources Research, v. 47, n. 4, p. 1-18, 2011. 
BESKOW, S.; MELLO, C.R.; NORTON, L.D.; DA SILVA, A.M. Performance of a distributed semi-conceptual hydrological model under tropical watershed conditions. Catena, v. 86, n. 3, p. 160-171, 2011.

BESKOW, S.; MELLO, C.R.; NORTON, L.D. Development, sensitivity and uncertainty analysis of LASH model. Scientia Agricola, v. 68, n. 3, p. 265-274, 2011.

BEVEN, K.J.; KIRKBY, M.J. A physically based, variable contributing area model of basin hydrology. Hydrological Sciences Bulletin, v. 24, n. 1, p. 43-69, 1979.

BRIGHENTI, T.M.; BONUMÁ, N.B.; CHAFFE, P.L.B. Calibração hierárquica do modelo SWAT em uma bacia hidrográfica Catarinense. Revista Brasileira de Recursos Hídricos, v. 21, n. 1, p. 53-64, 2016.

BUDYKO, M.I. Climate and Life. New York: Academic Press, 1974.

CASAGRANDE, L.; TOMASELLA, J.; DOS SANTOS ALVALÁ, R.C.; BOTTINO, M.J.; DE OLIVEIRA CARAM, R. Early flood warning in the Itajaí-Açu River basin using numerical weather forecasting and hydrological modeling. Natural Hazards, v. 88, n. 2, p. 741-757, 2017.

CHOU, S.; LYRA, A.; MOURÃO, C.; DERECZYNSKI, C.; PILOTTO, I.; GOMES, J.; BUSTAMANTE, J.; TAVARES, P.; SILVA, A.; RODRIGUES, D.; CAMPOS, D.; CHAGAS, D.; SUEIRO, G.; SIQUEIRA, G.; MARENGO, J. Assessment of climate change over South America under RCP 4.5 and 8.5 downscaling scenarios. American Journal of Climate Change, v. 3, n. 5, p. 512-527, 2014a.

CHOU, S.; LYRA, A.; MOURÃO, C.; DERECZYNSKI, C.; PILOTTO, I.; GOMES, J.; BUSTAMANTE, J.; TAVARES, P.; SILVA, A.; RODRIGUES, D.; CAMPOS, D.; CHAGAS, D.; SUEIRO, G.; SIQUEIRA, G.; MARENGO, J. Evaluation of the Eta simulations nested in three global climate models. American Journal of Climate Change, v. 3, n. 5, p. 438-454, 2014b.

COLLISCHONN, W.; ALLASIA, D.; DA SILVA, B.C.; TUCCI, C.E. The MGB-IPH model for large-scale rainfall-runoff modelling. Hydrological Sciences Journal, v. 52, n. 5, p. 878-895, 2007.

CUARTAS, L.A.; TOMASELLA, J.; NOBRE, A.D.; NOBRE, C.A.; HODNETT, M.G.; DE OLIVEIRA, S.M.; VON RANDOW, R.D.C.; TRANCOSO, E.; FERREIRA, M. Distributed hydrological modeling of a micro-scale rainforest watershed in Amazonia: Model evaluation and advances in calibration using the new HAND terrain model. Journal of Hydrology, v. 462-463, p. 15-27, 2012.

DUAN, Q.; SOROOSHIAN, S.; GUPTA, V. Effective and efficient global optimization for conceptual rainfall-runoff models. Water Resources Research, v. 28, n. 4, p. 10151031, 1992.

FALCK, A.S.; MAGGIONI, V.; TOMASELLA, J.; VILA, D.A.; DINIZ, F.L. Propagation of satellite precipitation uncertainties through a distributed hydrologic model: A case study in the Tocantins-Araguaia basin in Brazil. Journal of Hydrology, v. 527, p. 943-957, 2015.

GASH, J.H.C.; LLOYD, C.R.; LACHAUD, G. Estimating sparse forest rainfall interception with an analytical model. Journal of Hydrology, v. 170, n. 1-4, p. 79-86, 1995.
HUNT, J.D.; STILPEN, D.; FREITAS, M.A.V. A review of the causes, impacts and solutions for electricity supply crises in Brazil. Renewable and Sustainable Energy Reviews, v. 88, p. 208-222, 2018.

IPCC. Climate Change 2013: The Physical Science Basis, Contribution of Working Group I of the Intergovernmental Panel on Climate Change. Fifth Assessment Report of the Intergovernmental Panel on Climate Change. Cambridge: Cambridge University Press, 2013.

JARVIS, N.J. A simple empirical model of root water uptake. Journal of Hydrology, v. 107, n. 1-4, 1989.

LEY, R.; CASPER, M.C.; HELLEBRAND, H.; MERZ, R. Catchment classification by runoff behaviour with selforganizing maps (SOM). Hydrology and Earth System Sciences, v. 15, n. 9, p. 2947-2962, 2011.

LOPES, L.G.; RODRIGUEZ, D.A.; JÚNIOR, J.L.S.; MOHOR, G.S. Projeções de descargas extremas sob impactos das mudanças climáticas na Região Amazônica. Revista Brasileira de Cartografia, v. 69, n. 1, p. 209-227, 2017.

LYRA, A.; IMBACH, P.; RODRIGUEZ, D.; CHOU, S.C.; GEORGIOU, S.; GAROFOLO, L. Projections of climate change impacts on central America tropical rainforest. Climatic Change, v. 141, n. 1, p. 93-105, 2017.

LYRA, A., TAVARES, P., CHOU, S.C., SUEIRO, G., DERECZYNSKI, C., SONDERMANN, M., SILVA, A.; MARENGO, J.; GIAROLLA, A. Climate change projections over three metropolitan regions in Southeast Brazil using the non-hydrostatic Eta regional climate model at 5-km resolution. Theoretical and Applied Climatology, v. 132, n. 1-2, p. 663-682, 2018.

MARENGO, J.A.; NOBRE, C.A.; SELUCHI, M.E.; CUARTAS, A.; ALVES, L.M.; MENDIONDO, E.M.; OBREGÓN, G.; SAMPAIO, G. A seca e a crise hídrica de 2014-2015 em São Paulo. Revista USP, n. 106, p. 31-44, 2015.

MARTINS, M.A.; TOMASELLA, J.; RODRIGUEZ, D.A.; ALVALÁ, R.C.; GIAROLLA, A.; GAROFOLO, L.L.; SIQUEIRA JÚNIOR, J.L.; PAOLICCHI, T.L.C.L.; PINTO, G.L. Improving drought management in the Brazilian semiarid through crop forecasting. Agricultural Systems, v. 160, p. 21-30, 2018.

MARTINS, M.A.; TOMASELLA, J.; DIAS, C.G. Maize yield under a changing climate in the Brazilian Northeast: Impacts and adaptation. Agricultural Water Management, v. 216, p. 339-350, 2019.

MELLO, C.R.D.; NORTON, L.D.; CURI, N.; YANAGI, S.N.M. Sea surface temperature (SST) and rainfall erosivity in the Upper Grande River Basin, southeast Brazil. Ciência e Agrotecnologia, v. 36, n. 1, p. 53-59, 2012.

MELLO, C.R.; ÁVILA, L.F.; VIOLA, M.R.; CURI, N.; NORTON, L.D. Assessing the climate change impacts on the rainfall erosivity throughout the twenty-first century in the Grande River Basin (GRB) headwaters, southeastern Brazil. Environmental Earth Sciences, v. 73, n. 12, p. 86838698, 2015.

MELO, P.A. Desempenho de Modelos Hidrológicos em uma Bacia Hidrográfica de Cabeceira. Dissertação de Mestrado em Recursos Hídricos em Sistemas Agrícolas, Universidade Federal de Lavras, Lavras, 90 p., 2019. 
MESINGER, F.; CHOU, S.C.; GOMES, J.L.; JOVIC, D.; BASTOS, P.; BUSTAMANTE, J.F.; LAZIC, L.; LYRA, A. A.; MORELLI, S.; RISTIC, I.; VELJOVIC, K. An upgraded version of the Eta model. Meteorology and Atmospheric Physics, v. 116, n. 3-4, p. 63-79, 2012.

MONTEITH, J.L. Evaporation and surface temperature. Quarterly Journal of the Royal Meteorological Society, v. 107, n. 451, p. $1-27,1981$.

MORIASI, D.N.; GITAU, M.W.; PAI, N.; DAGGUPATI, P. Hydrologic and water quality models: Performance measures and evaluation criteria. Transactions of the ASABE, v. 58, n. 6 , p. $1763-1785,2015$.

NASH, J.E.; SUTCLIFFE, J.V. River flow forecasting through conceptual models part I - A discussion of principles. Journal of Hydrology, v. 10, n. 3, p. 282-290, 1970.

NETO, J.D.O.M.; SILVA, A.A.; MELLO, C.D.; JÚNIOR, A.V.M. Simulação hidrológica escalar com o modelo SWAT. Revista Brasileira de Recursos Hídricos, v. 19, n. 1, p. 177-188, 2014.

NÓBREGA, M.T.; COLLISCHONN, W.; TUCCI, C.E.M.; PAZ, A.R. Uncertainty in climate change impacts on water resources in the Rio Grande Basin, Brazil. Hydrology and Earth System Sciences, v. 15, n. 2, p. 585-595, 2011.

OLIVEIRA, K.D.; TOMASELLA, J.; SANCHES, L.D. Spatialtemporal analysis of the climatic and anthropogenic influences on runoff in the Jucu River Basin, Southeastern Brazil. Land Degradation and Development, v. 30, n. 17, p. 2073-2087, 2019.

OLIVEIRA, V.A.; MELLO, C.R.; VIOLA, M.R.; SRINIVASAN, R. Assessment of climate change impacts on streamflow and hydropower potential in the headwater region of the Grande river basin, southeastern Brazil. International Journal of Climatology, v. 37, n. 15, p. 5005-5023, 2017.

REBOITA, M.S.; GAN, M.A.; ROCHA, R.P.D.; AMBRIZZI, T. Regimes de precipitação na América do Sul: uma revisão bibliográfica. Revista Brasileira de Meteorologia, v. 25, n. 2, p. 185-204, 2010.

RENNÓ, C.D.; NOBRE, A.D.; CUARTAS, L.A.; SOARES, J.V.; HODNETT, M.G.; TOMASELLA, J. HAND, a new terrain descriptor using SRTM-DEM: Mapping terra-firme rainforest environments in Amazonia. Remote Sensing of Environment, v. 112, n. 9, p. 3469-3481, 2008.

RODRIGUEZ, D.A.; TOMASELLA, J. On the ability of largescale hydrological models to simulate land use and land cover change impacts in Amazonian basins. Hydrological Sciences Journal, v. 61, n. 10, p. 1831-1846, 2016.

SALES, D.C.; COSTA, A.A.; SILVA, E.M.D.; VASCONCELOS, F.D.C.; CAVALCANTE, A.D.M.B.; MEDEIROS, S. D.S.; MARIN, A.M.P.; SULLYANDRO, O.G.; ARAÚJO
JUNIOR, L.M.; PEREIRA, J.M.R. Projeções de mudanças na precipitação e temperatura no nordeste Brasileiro utilizando a técnica de downscaling dinâmico. Revista Brasileira de Meteorologia, v. 30, n. 4, p. 435-456, 2015.

SAMPAIO, G.; DIAS, P.LS. Evolução dos modelos climáticos e de previsão de tempo e clima. Revista USP, n. 103, p. 4154, 2014.

SANTOS, C.A.; ROCHA, F.; RAMOS, T.B.; ALVES, L.M.; MATEUS, M.; OLIVEIRA, R.P.D.; NEVES, R. Using a hydrologic model to assess the performance of regional climate models in a semi-arid watershed in Brazil. Water, v. 11, n. 1, p. 1-17, 2019.

SIQUEIRA JÚNIOR, J.L.; TOMASELLA, J.; RODRIGUEZ, D. A. Impacts of future climatic and land cover changes on the hydrological regime of the Madeira River basin. Climatic Change, v. 129, n. 1-2, p. 117-129, 2015.

TEUTSCHBEIN, C.; SEIBERT, J. Bias correction of regional climate model simulations for hydrological climate-change impact studies: Review and evaluation of different methods. Journal of Hydrology, v. 456, p. 12-29, 2012.

VIOLA, M.R.; MELLO, C.R.; BESKOW, S.; NORTON, L.D. Impacts of land-use changes on the hydrology of the Grande River basin headwaters, southeastern Brazil. Water Resources Management, v. 28, n. 13, p. 4537-4550, 2014.

VIOLA, M.R.; MELLO, C.R.; CHOU, S.C.; YANAGI, S.N.; GOMES, J.L. Assessing climate change impacts on Upper Grande River basin hydrology, southeast Brazil. International Journal of Climatology, v. 35, n. 6, p. 1054-1068, 2015.

YAMAGUCHI, Y.; KAHLE, A.B.; TSU, H.; KAWAKAMI, T.; PNIEL, M. Overview of advanced spaceborne thermal emission and reflection radiometer (ASTER). IEEE Transactions on Geoscience and Remote Sensing, v. 36, n. 4, p. 1062-1071, 1998.

YAPO, P.O.; GUPTA, H.V.; SOROOSHIAN, S. Automatic calibration of conceptual rainfall-runoff models: Sensitivity to calibration data. Journal of Hydrology, v. 181, n. 1-4, p. 23-48, 1996.

ZÁKHIA, E.M.S.; ALVARENGA, L.A.; TOMASELLA, J.; MARTINS, M.A. Avaliação de projeções climáticas para uma bacia experimental, localizada na região sul de Minas Gerais. Revista Ibero-Americana de Ciências Ambientais, v. 11, n. 6, p. 234-250, 2020.

ZHAO, R.J. The Xinanjiang model applied in China. Journal of Hydrology, v. 135, n. 1-4, p. 371-381, 1992.

License information: This is an open-access article distributed under the terms of the Creative Commons Attribution License (type CC-BY), which permits unrestricted use, distribution and reproduction in any medium, provided the original article is properly cited. 